\title{
Pediatric traumatic brain injury in Zimbabwe: A prospective cohort study
}

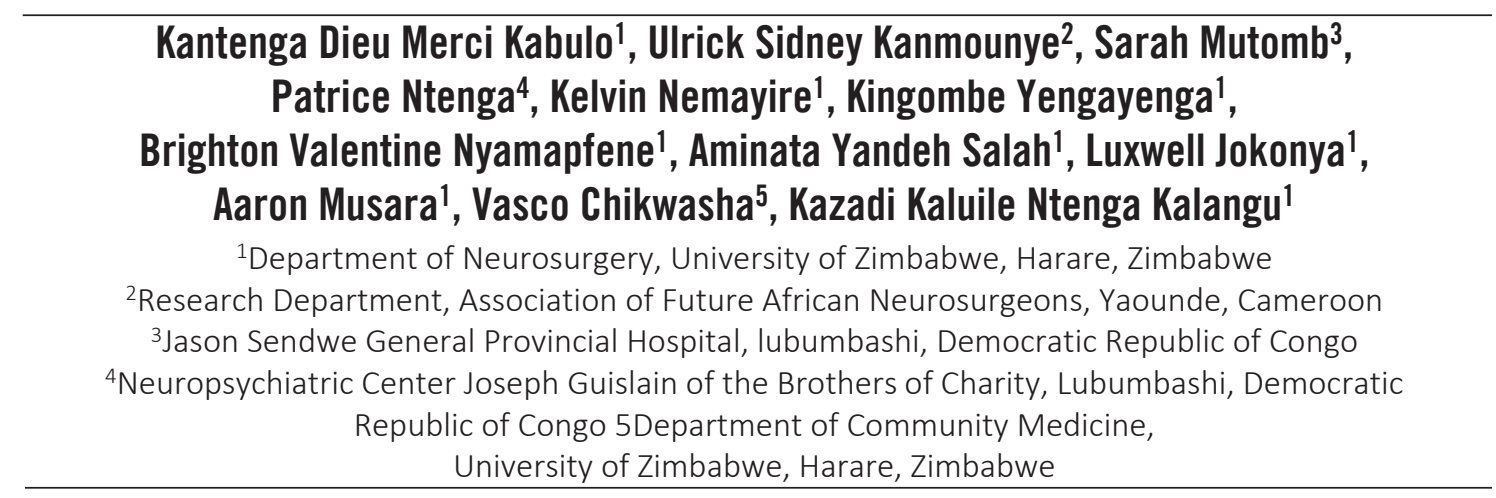

\begin{abstract}
Background. Traumatic brain injury (TBI) imposes an enormous burden on health systems and it is the most frequent cause of hospitalization in children. This study aimed at describing the causes, presentation, management, and outcome of children with TBI admitted at a tertiary referral hospital in Harare, Zimbabwe.

Methods. This prospective cohort study was conducted with a convenience sample of children aged $\leq 12$ years and admitted with TBI at the study site from June 2018 to May 2019. The children were followed from their admission to one-month post-discharge. Sociodemographic, clinical, and neuroimaging data were collected. The median length of stay was calculated and the Chi-square, Fisher's exact, and Kruskal Wallis tests were used.

Results. 84 children with TBI were recruited. Most were males $(66.7 \%)$ and $(56.0 \%)$ had sustained TBI following a motor vehicle accident. An initial period of loss of consciousness that lasted a median of $6.5(\mathrm{IQR}=4.8)$ hours was noted in $60.7 \%$ of patients. The most common symptom at presentation was headache $(61.9 \%)$, and mild TBI was the most common type of TBI. Skeletal injuries were the most encountered associated injuries (13.1\%) and the majority of patients were managed non-operatively - 79 (94.0\%). Most patients $(56.0 \%)$ experienced upper good recovery at one-month follow-up.

Conclusions. Motor vehicle accidents are the main cause of pediatric TBI in Zimbabwe. Most patients do not require surgical treatment and have a good recovery.
\end{abstract}

Keywords: global neurosurgery, outcome, pediatric, traumatic brain injury, Zimbabwe

\begin{abstract}
Abbreviation list
GCS - Glasgow coma scale LOS - length of stay

GOS - Glasgow outcome scale TBI - traumatic brain injury

LOC - loss of consciousness ICU - intensive care unit
\end{abstract}

\section{INTRODUCTION}

Traumatic brain injury (TBI) is among the oldest and most common medical afflictions. Between 10 and $50 \%$ of skulls of prehistoric humans show evidence of cranial trauma (1). With time, our understanding of the pathophysiology, neuroimaging, and management of TBI has improved.
We now understand that the magnitude of damage to cerebral tissues following head trauma is determined by primary and delayed secondary injuries (2). Primary injuries are caused by the kinetic energy delivered by external physical forces (blows, acceleration/deceleration, and rotation) at the time of impact, resulting in skull fractures, hematomas, and deformation and destruction of brain 
tissue, including contusions and axonal injury. $\mathrm{Nu}-$ merous secondary injuries that almost inevitably worsen the primary injury develop over time with activation of multiple molecular and cellular pathways and may be promoted by secondary insults (e.g., hypotension, hypoxia, hypocarbia, hyperglycaemia, hypo-/hyperthermia, electrolyte disorders, epileptic seizures exacerbating the imbalance between energy expenditure and supply) (2).

Computer tomography (CT) scans play an important role in the workup of TBI. In children, significant findings on head CT scan post-TBI are rare, hence multiple effective clinical predictive criteria have been developed to avoid unnecessary CT scan use in this population group. For this reason, special attention is given to children, especially if younger than 2 years of age, before ordering a CT scan (3).

Most TBI cases are mild (Glasgow coma scale GCS 13-15), approximately $10 \%$ are moderate (GCS 9-12) and an additional 10\% are severe (GCS 3-8). Approximately 1.1 million are mild TBI injuries. The incidence of TBI is about 15 cases per 100,000 people and overall, TBI mortality is 17 per 100,000 for out-of-hospital patients and 6 per 100,000 for in-hospital patients (4).

Children with TBI demonstrate more severe deficits in emotional regulation and executive functioning than adults, due to the disruption of normal neurological development (5). Since children are still in the process of brain maturation, they ultimately have fewer compensatory skills available to readjust cognitive functioning and processes after brain injury (5). Numerous studies have found that a lower age at the time of injury results in more significant impairment later in Brain development. As a result, even a mild injury could lead to a lifelong disability $(6,7)$. As such, TBI is gaining recognition as a disorder of public health concern, particularly in Zimbabwe (8). This study aimed at determining the causes, presentation, management,and outcome of children under the age of 12 with TBI admitted at a tertiary referral hospital in Harare, Zimbabwe.

\section{MATERIAL AND METHODS}

\section{Study design and setting}

This prospective cohort study was conducted at a tertiary referral hospital and the largest neurosur- gical center in the country (9). Consecutive children admitted with history of TBI were recruited into the study in convenience sampling and the children were followed up for one-month post-discharge.

The sample population included all patients aged 12 years and below (definition of pediatric age in Zimbabwe) who were admitted with a diagnosis of TBI from June 2018 to May 2019. A data collection tool that captured sociodemographic (sex, age, address), clinical (GCS, GOS, clinical signs), neuroimaging data was used. Consent forms were signed by the guardians of the patients and the study was authorized by the Joint Research Ethics Committee (Ref: 142/18 of June 6, 2018).

\section{Data analysis}

Missing value analysis was used to identify missing data and their pattern of missing. Multiple imputations were then used to compute the missing data. Also, summary descriptive analyses were used to compute proportions and counts (for qualitative variables) and measures of central tendency and spread (for quantitative variables). Next, tests of normality were used to determine the normality of quantitative variables.

The Kaplan-Meier analysis was used to determine the median length of stay (LOS) and by GCS category. Also, the Chi-square, Fisher's exact, and Kruskal Wallis tests were used to evaluate the relationship between individual independent variables and the dependent variable (Glasgow outcome score - GOS). Finally, non-parametric multivariate analyses were used to identify significant variables and confounders. A p value $<0.05$ was considered statistically significant.

\section{RESULTS}

\section{Sociodemographic data}

87 patients were eligible in our study but 3 (3.4\%) refused to sign the consent and were therefore excluded from the study leaving 84 patients aged $5.7 \pm 3.1$ years recruited into the study. 56 (66.7\%) patients were male, 47 (56\%) were referrals from other cities outside Harare. 47 (56.0\%) patients had been involved in a motor vehicle accident (Table 1). 
TABLE 1. Sociodemographic characteristics of Zimbabwean children with traumatic brain injury

\begin{tabular}{|l|l|}
\hline Characteristics & Frequency (Percentage, $\mathbf{N}=84)$ \\
\hline Sex & \\
Female & $28(33.3)$ \\
Male & $56(66.7)$ \\
Address & $35(41.7)$ \\
Harare & $49(58.3)$ \\
Out of Harare & \\
Cause of injury & $8(9.5)$ \\
Blow to the head & $1(1.2)$ \\
Assault & $7(8.3)$ \\
Incidental & $29(34.5)$ \\
Fall & $14(16.7)$ \\
From furniture & $9(10.7)$ \\
From a tree & $6(7.1)$ \\
From a scotch cart & $47(56.0)$ \\
Motor vehicle accident & $30(35.7)$ \\
Passenger & $17(20.2)$ \\
Pedestrian &
\end{tabular}

\section{Clinical presentation and neuroimaging}

Patients had been hit in the forehead ( $\mathrm{n}=17$, $20.2 \%)$ or the back of the head ( $\mathrm{n}=13,15.5 \%)$ and they presented with headache $(n=52,61.9 \%)$ and an initial loss of consciousness $(\mathrm{n}=51,60.7 \%)$ that lasted a median of $6.5(\mathrm{IQR}=4.8)$ hours. Moreover, the majority of patients $(n=58,69.0 \%)$ had mild TBI (Table 2).

TABLE 2. Clinical presentation of Zimbabwean children with traumatic brain injury

\begin{tabular}{|l|l|}
\hline $\begin{array}{l}\text { History, presentation, and } \\
\text { findings }\end{array}$ & $\begin{array}{l}\text { Frequency } \\
\text { (Percentage, N = 84) }\end{array}$ \\
\hline $\begin{array}{l}\text { Location of impact } \\
\text { Back of the head } \\
\text { Face }\end{array}$ & $13(15.5)$ \\
Forehead & $3(3.6)$ \\
Left side & $17(20.2)$ \\
Right side & $8(9.5)$ \\
Top of the head & $5(6.0)$ \\
Presenting symptoms & $7(8.3)$ \\
Blurred vision & \\
Confusion & $1(1.2)$ \\
Dizziness & $11(13.1)$ \\
Headache & $2(2.4)$ \\
Inability to walk & $52(61.9)$ \\
Inconsolable crying & $2(2.4)$ \\
Loss of consciousness & $10(11.9)$ \\
Neck pain & $51(60.7)$ \\
Not communicating & $3(3.6)$ \\
Seizures & $18(21.4)$ \\
Vomiting & $18(21.4)$ \\
Glasgow coma scale & $11(13.1)$ \\
Mild & \\
Moderate & $58(69.0)$ \\
Severe & $18(21.4)$ \\
Clinical findings & $8(9.5)$ \\
Anisocoria & \\
Hemiparesis (-plegia) & \\
Paraparesis (-plegia) & $2(2.4)$ \\
& $4(4.8)$ \\
& $1(1.2)$ \\
\hline
\end{tabular}

The majority of patients $(n=69,82.1 \%)$ had a head CT scan, $10(11.9 \%)$ patients had a skull $\mathrm{x}$-ray, and $5(6.0 \%)$ could not afford neuroimaging.
28 children (33.3\%) had brain contusions, 26 (31.0\%) had a skull fracture, and $22(26.2 \%)$ had brain edema (Figure 1). The children with skull fractures $(\mathrm{n}=26)$ had depressed fractures $(13.1 \%$, $\mathrm{n}=11)$, basilar skull fractures $(\mathrm{n}=7,8.3 \%)$, and linear skull fractures $(\mathrm{n}=8,9.5 \%)$. Also, some patients had lesions of other organ systems: skeletal $(\mathrm{n}=11,13.1 \%)$, chest $(\mathrm{n}=2,2.4 \%)$, and spine $(\mathrm{n}=2,2.4 \%)$.

\section{Treatment and outcome}

Most children ( $\mathrm{n}=77,91.7 \%)$ were managed conservatively and surgical treatment was indicated for depressed skull fracture, tension pneumocephalus and debridement and suture of laceration. The overall median LOS was $4.0(95 \% \mathrm{CI}=3.4$ 4.6) days -that is a median LOS of $3.0(95 \% \mathrm{CI}=$ 3.4-4.6) days for patients with mild TBI, 7.0 (95\% $\mathrm{CI}=3.4-4.6)$ days for patients with moderate TBI $(95 \% \mathrm{CI}=4.9-9.1)$, and $10.0(95 \% \mathrm{CI}=9.2-10.8)$ days for patients with severe TBI (Figure 2).

Most $(n=47,56.0)$ patients had a GOS corresponding to upper good recovery at one-month follow-up, $26(31.0 \%)$ had a lower good recovery, and $3(3.6 \%)$ were lost to follow-up (Figure 3 ).

Lower GOS scores were associated with loss of consciousness (Kruskal Wallis $=13.15, \mathrm{p}=0.02$ ), headache (Kruskal Wallis $=28.71, \mathrm{p}<0.01)$, GCS (Kruskal Wallis $=51.42, \mathrm{p}<0.01$ ), anisocoria (Kruskal Wallis $=49.24, \mathrm{p}<0.01$ ), paraplegia (-paresis) (Kruskal Wallis $=80.00, \mathrm{p}<0.01)$, brain edema (Kruskal Wallis $=11.76, \mathrm{p}=0.04)$, and a spinal injury (Kruskal Wallis $=40.57, \mathrm{p}<0.01$ ). Also, higher GOS scores were associated with the use of mannitol (Kruskal Wallis $=31.52, \mathrm{p}<0.01$ ) and the treatment of existing infection (Kruskal Wallis $=20.06, p=0.01$ ) and seizures (Kruskal Wallis $=80.00, \mathrm{p}<0.01)$.

\section{Multivariate analysis - significant variables and confounders}

After multivariate analysis GOS was associated with loss of consciousness (LOC) $(p=0.01)$, GCS $(p<0.01)$, brain edema $(p=0.03)$.

The confounding relationship between the variables below was confirmed using multivariate analysis. Lower GCS was associated with a history LOC $(\mathrm{R}=-0.61, \mathrm{p}<0.01)$ and paraplegia (-paresis $)(R=0.32, p<0.01)$. Similarly, headache was 


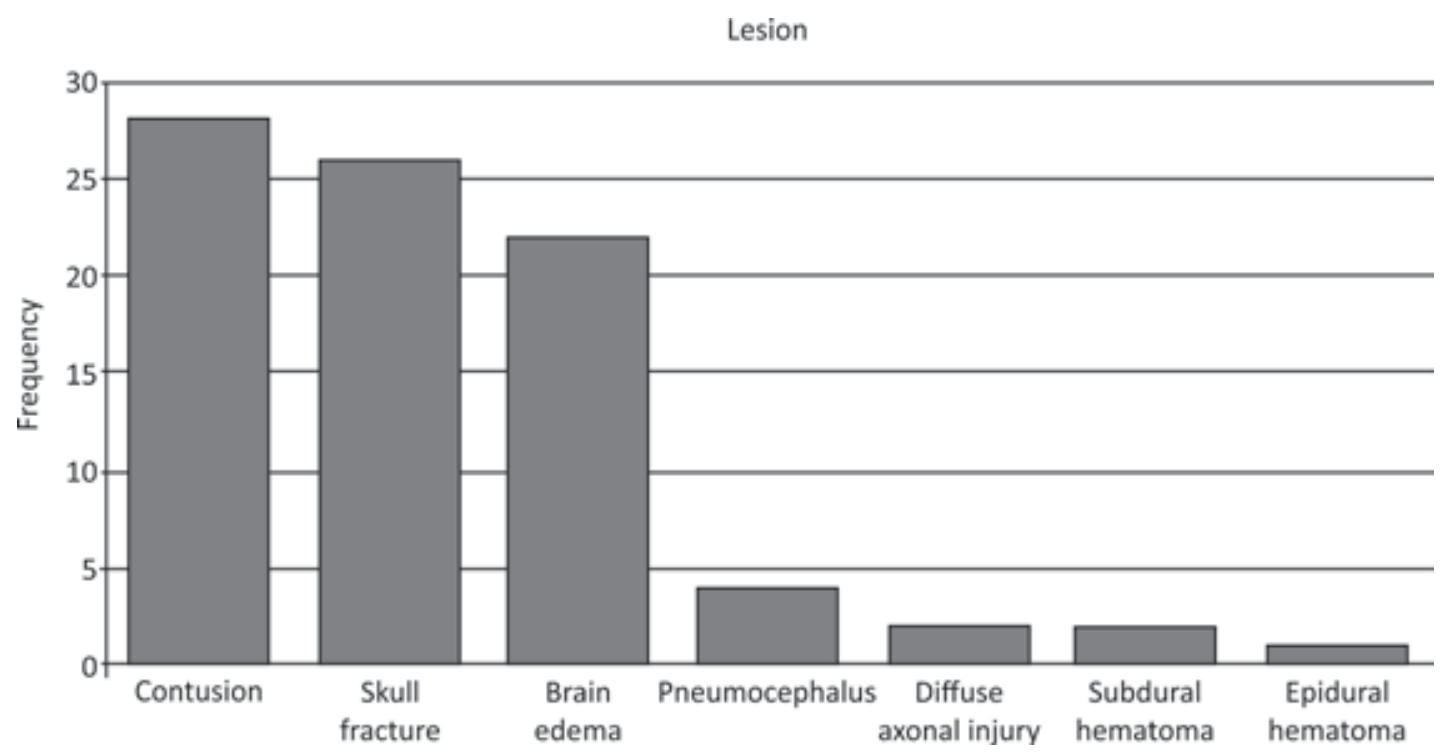

FIGURE 1. Frequency of lesions

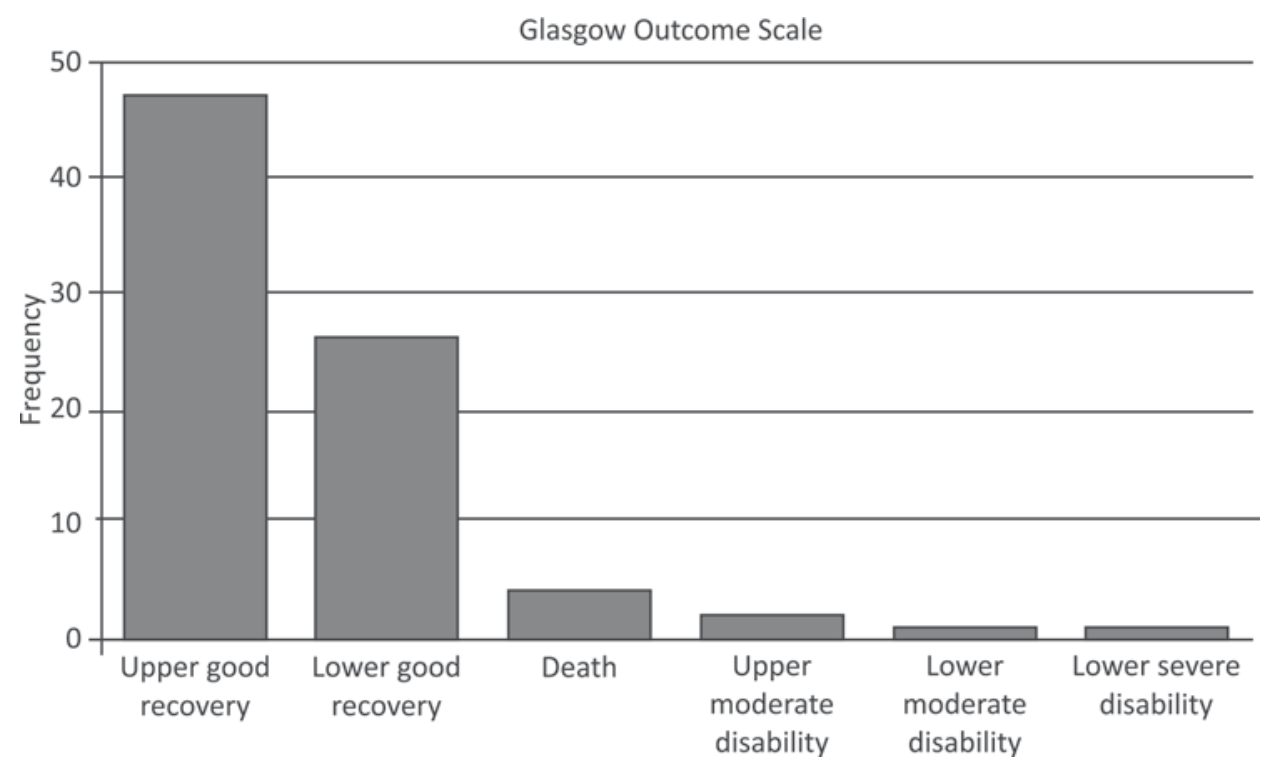

FIGURE 2. Frequency of recovery and disability

associated with a history of LOC $(\mathrm{R}=-0.60, \mathrm{p}<$ $0.01)$ and paraplegia (-paresis) $(\mathrm{R}=0.31, \mathrm{p}<0.01)$. In addition, LOC was associated with spinal injuries $(\mathrm{R}=-0.60, \mathrm{p}<0.01)$, anisocoria $(\mathrm{R}=-0.60$, $\mathrm{p}<0.01)$, mannitol administration $(\mathrm{R}=-0.61$, $\mathrm{p}<0.01)$, and antibiotic administration $(\mathrm{R}=-0.61$, $\mathrm{p}<0.01)$.

\section{DISCUSSION}

\section{Epidemiology}

Across all age groups, the incidence rates of TBI are higher in boys than in girls (10). Similar to various other studies, the majority of our patients were males $66.7 \%$ which corresponds with what was found by Kanwaljeet Garg et al. who found in their study that $69 \%$ were boys (11). However, Sambasivan et al. reported an equal number of males and females in his series (12). Our observation corresponds with the observations made by other authors. The reason is that boys exhibit more risky behavior when playing compared to girls and are frequently affected because they are more involved in outdoor activities (13). Although gender differences were important in the rate of injury, they did not appear to adversely affect the neurological outcome at one month.

In our study, the causes of TBI were motor vehicle accidents, followed by fall then blow to the head. This contrasts with Japan where fall is the 


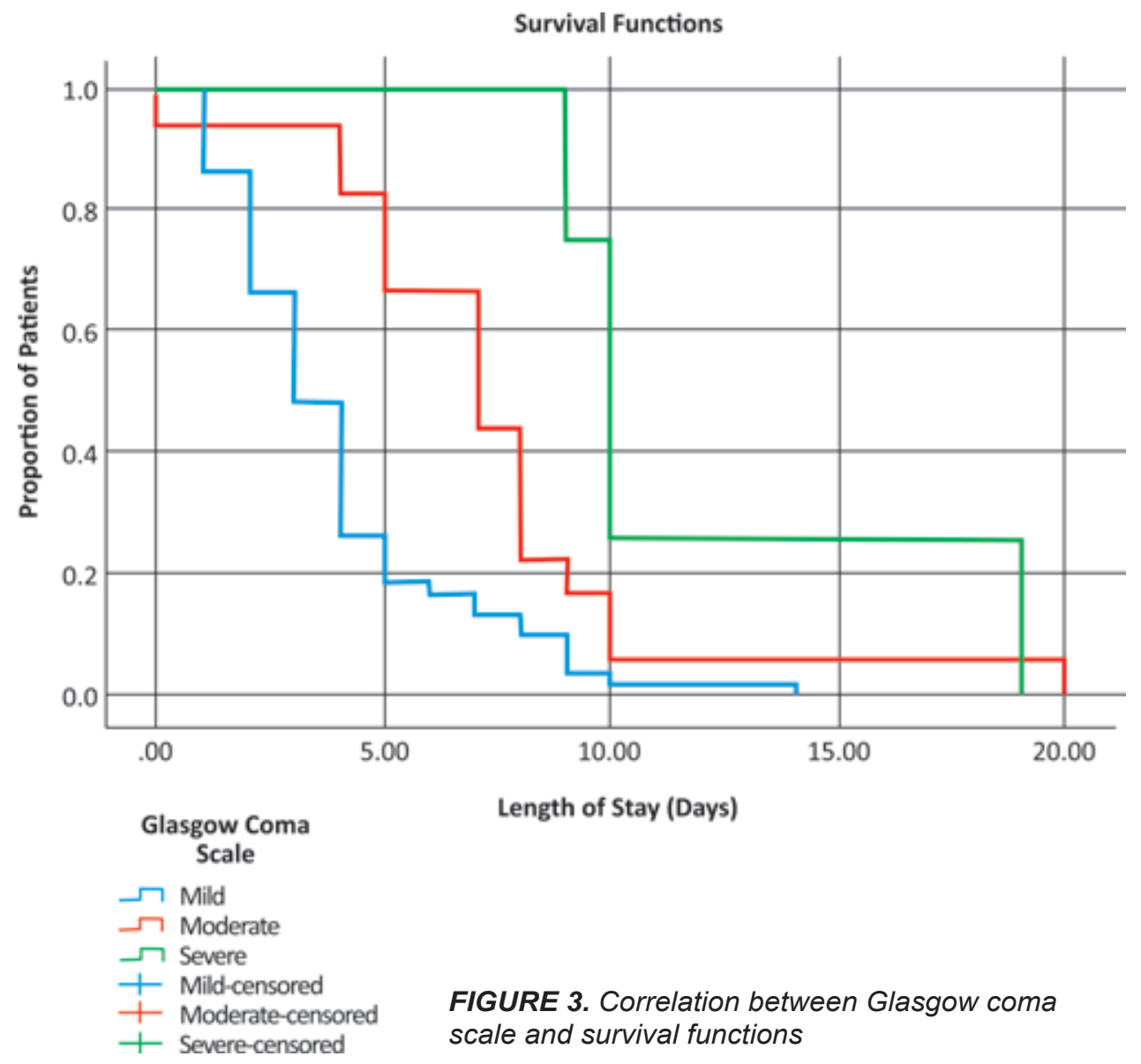

leading cause of pediatric TBI (10-12). However, our findings concord with the findings in Nigeria, Tunisia, and South Africa $(12,14,15)$. Children in urban areas are at risk of motor vehicle accidents at this age because they often play in the streets unsupervised. There is also a lack of safety measures in place where they are playing. In rural areas, the villages are often adjacent to highways or to roads that are used by heavy motor vehicles. Moreover, traffic laws are not universally observed (16).

We had a suspected case of abusive head trauma in an infant aged 6 months. Abusive head trauma is frequent particularly in young infants below two years of age; approximately 30/100,000 infants under 1 year are hospitalized for abusive head trauma (10). Diagnosis of non-accidental head injury may be difficult, as most infants present with non-specific clinical findings and without external signs of trauma. Neuroimaging plays a fundamental role both for medical management and medicolegal aspects of child abuse (17).

\section{Clinical presentation and outcomes}

The most common symptom at presentation was headache (18). The presence of symptoms such as nausea, headache, and vomiting, and their impact on decision making has been considered conflicting especially in the pediatric population. Since these symptoms may be absent in children, the history in this case needs to be gathered rapidly but remains essential. A description of the trauma, the presence or absence of seizure activity, evidence of LOC at the time of impact, or change in the level of consciousness will all help guide the diagnosis and management of these children (19).

The forehead was the most common site of impact followed by the back of the head. This can be explained by the prominent forehead seen in young children which increases the chance that a force can directly impact the frontal scalp and underlying skull (10).

The children commonly presented associated injuries to other organs or body systems. These were in decreasing order, skeletal, chest, and spinal injuries. Our findings are similar to those of Mabrouk Bahloul et al.: skeletal injuries (25.1\%), chest trauma (9.5\%), and spinal trauma (1.3\%) (14). These findings can be explained by the point of impact and energy associated with a motor vehicle accident in which the child is a pedestrian. 
Children are hit on the lower limbs before they fall on their heads (20).

Most patients were managed conservatively and only a handful had surgery. Moreover, mortality was relatively low. Although most pediatric head injuries are mild and require evaluation and monitoring, TBI is still the most common cause of trauma-related death in children (21).

The overall median LOS was $4.0 \quad(95 \%$ $\mathrm{CI}=3.4-4.6)$ days and it increased with a worsening GCS, in a multicenter retrospective cohort study of adults suggest that hospital and ICU LOS for TBI admissions are 56\% and $119 \%$ longer than expected according to all-diagnosis admissions, respectively - geometric mean total LOS was 1day longer than geometric mean index LOS (12.6 versus 11.7 days) (22). This shows that the pediatric population recovers fast compared to adults and does not require a long stay in the hospital. Patients with initial loss of consciousness, additional injuries, or those suspected to be cases of abusive head trauma may require long hospitalization (23).

For diagnostic and research purposes there is a need to categorize patients along the spectrum of severity from mild, moderate to severe and very severe although opinion differs as to where each of these boundaries are set, or how they are defined (24). In our study most patients had mild TBI, which is consistent with other studies in which the most common type of pediatric TBI as mild TBI (21). The high prevalence of mild TBI has been attributed to the unique biomechanical properties for TBI in the pediatric population which, due to a combination of higher plasticity and deformity, whereby external forces are absorbed in a different manner compared to adults (10). Unlike in adults, the skull of the infant is not rigid and the open skull sutures function as joints, allowing a low degree of movement in response to mechanical stress.

Most patients had a head CT scan done as part of routine workup and few had a skull X-ray done. A few patients could not afford the CT scan or were unable to get a CT scan because the machine was not functioning, in Zimbabwe almost seventy percent of equipment (13/19 units, $68 \%)$ is in the major cities, and more than $60 \%$ (12/19units, 63\%) in the private sector. The disparity in access between the public and private sectors (1:16) is comparable to that for plain radiography which is difficult for most of the patient to afford private (25).
Head CT is the gold standard for TBI because it is accurately detected structural damage and abnormalities in the acute TBI setting (26). However, during the last decades there have been debates about the possible detrimental effect of CT scanning on children because they have a longer life expectancy and are more vulnerable to radiation-induced malignancies due to more dividing cells $(27,28)$. That is why Pinto et al. state that especially in childhood, conventional MRI compared to CT scan is a better imaging tool due to its high sensitivity and specificity, better correlation with the outcome, and lack of radiation $(29,30)$. Unfortunately MRIs are less accessible financially and geographically to the average Zimbabwean family.

Skull fractures were the second most common neuroimaging finding. Of the patients who sustained skull fractures, most had depressed fractures (Ping-Pong fractures), basilar skull fractures and linear. Although these might seem alarming, the majority of pediatric skull fractures can be managed conservatively (31). Which is in keeping with our study where the majority of our patients were managed conservatively. Growing fractures are rare (32) and we did not observe any in our study. In a recent report, $2 \mathrm{D}$ plus $3 \mathrm{D} \mathrm{CT}$ together was shown to have high sensitivity in diagnosing linear fractures in most children and increased specificity in children under two years, with concurrent intracranial lesions detected in $15 \%-30 \%$ of these patients (31). As noted earlier, a head CT scan might not always be available in Zimbabwe and in these cases, the neurosurgery provider will rely on indirect signs to diagnose injuries. For example, providers will look for subcutaneous swelling, lacerations, bruises and abrasions that indicate a high suspicion of skull fractures (33).

Lower GOS scores were associated with initial loss of consciousness, and low GCS was associated with a history of LOC. Also, there was a significant association between the GCS and the GOS and there was no significant association between the cause of injury and GCS. The majority of patients in Zimbabwe are brought to the emergency department by relatives or bystanders in private vehicles because the prehospital emergency medical services are under-resourced. There is a need for a harmonized protocol for the treatment of children with traumatic brain injury for all hospitals. This would help to standardise care and improve 
the outcomes. The protocol can also include pre-hospital care by trained personnel to reduce risk of secondary brain insult (34).

There were a few limitations to our study. The first limitation is that data were censored because some patients could not afford a CT scan or the machine was not functioning. Furthermore, our results are hospital-based and this limits the generalization of the epidemiological findings. The follow-up period was short and could have led to an under-estimation of the morbidity of TBI in Zimbabwean children and minimise post traumatic sequelae since it is known that children suffer more cognitive and executive disorders than adults. For example, young children with linear skull fracture must be followed up long enough to exclude a growing fracture.

Conflict of interest: none declared

Financial support: none declared

\section{REFERENCES}

1. Diaz-Arrastia R, Vos PE. Traumatic Brain Injury. Oxford: John Wiley \& Sons, 2015.

2. Stocker RA. Intensive Care in Traumatic Brain Injury Including Multi-Modal Monitoring and Neuroprotection. Med Sci. 2019;7(3):37.

3. Polinder S, Cnossen MC, Real RG, Covic A, Gorbunova A, Voormolen DC, et al. A multidimensional approach to postconcussion symptoms in mild traumatic brain injury. Front Neurol. 2018;9:1113.

4. Abdelmalik PA, Draghic N, Ling GS. Management of moderate and severe traumatic brain injury. Transfusion. 2019 Apr;59(S2):1529-38.

5. Pediatric Traumatic Brain Injury: Outcomes and Rehabilitation. Textbook of Pediatric Neurosurgery. 2017:1-28.

6. Alghnam S, AlSayyari A, Albabtain I, Aldebasi B, Alkelya M. Long-term disabilities after traumatic head injury (THI): a retrospective analysis from a large level-I trauma center in Saudi Arabia. Inj Epidemiol. 2017;4(1):29.

7. McKinlay A, Linden M, DePompei R, Aaro Jonsson C, Anderson V, Braga $L$, et al. Service provision for children and young people with acquired brain injury: Practice recommendations. Brain Inj. 2016;30(13-14):1656-1664.

8. Ministry of Health and Child Care - Rehabilitation [Internet]. [cited 2020 Jul 15].

9. Parirenyatwa Hospital. In: Wikipedia [Internet]. 2019 [cited 2020 Jul 15]. Available at: https://en.wikipedia.org/w/index. php?title=Parirenyatwa_Hospital\&oldid=918130496.

10. Araki T, Yokota H, Morita A. Pediatric Traumatic Brain Injury: Characteristic Features, Diagnosis, and Management. Neurol Med Chir (Tokyo). 2017 Feb 15;57(2):82-93.

11. Nitnaware AS, Vagha J, Meshram R. Clinical profile of pediatric head injury. J Datta Meghe Inst Med Sci Univ. 2017;12(3):191.

12. Elachi IC, Yongu WT, Odoyoh O-OD, Mue DD, Ogwuche El, Ahachi $\mathrm{CN}$. An epidemiological study of the burden of trauma in Makurdi, Nigeria. Int J Crit IIIn Inj Sci. 2015;5(2):99.

13. Singh D, Singh SP, Kumaran M, Goel S. Epidemiology of road traffic accident deaths in children in Chandigarh zone of North West India. Egypt J Forensic Sci. 2016 Sep 1;6(3):255-60.

14. Bahloul M, Chaari A, Chabchoub I, Medhyoub F, Dammak H, Kallel $\mathrm{H}$, et al. Outcome analysis and outcome predictors of traumatic head injury in childhood: Analysis of 454 observations. J Emerg Trauma Shock. 2011;4(2):198.
Notwithstanding all these limitations, our study has the merit of depicting a comprehensive picture of pediatric TBI in Zimbabwe.

\section{CONCLUSIONS}

Motor vehicle accidents are the main cause of pediatric TBI in Zimbabwe and most patients present with headaches and seizures. The treatment of pediatric mild TBI is almost exclusively conservative and most patients recover well. Some Zimbabwean families experience financial challenges in getting neuroimaging and abusive head trauma is not uncommon. A more reliable and affordable CT scan is highly recommended at Parirenyatwa to ensure easier access.
15. Levin K. Paediatric traumatic brain injury in South Africa: some thoughts and considerations. Disabil Rehabil. 2004;26(5):306-314.

16. Muvuringi MP. Road traffic accidents in Zimbabwe, influencing factors impact and strategies. Dev Policy Pract Vrije Unuversity Amst KIT R Trop Inst. 2012.

17. Rajaram S, Batty R, Rittey CD, Griffiths PD, Connolly DJ. Neuroimaging in non-accidental head injury in children: an important element of assessment. Postgrad Med J. 2011 May; 87(1027):355-61.

18. Hergenroeder GW, Redell JB, Moore AN, Dash PK. Biomarkers in the clinical diagnosis and management of traumatic brain injury. Mol Diagn Ther. 2008;12(6):345-358.

19. Gelineau-Morel RN, Zinkus TP, Le Pichon JB. Pediatric Head Trauma: A Review and Update. Pediatr Rev. 2019;40(9):468.

20. Martin JL, Lardy A, Laumon B. Pedestrian Injury Patterns According to Car and Casualty Characteristics in France. Ann Adv Automot Med Annu Sci Conf. 2011 Oct;55:137-46.

21. Dewan MC, Rattani A, Gupta S, Baticulon RE, Hung Y-C, Punchak $\mathrm{M}$, et al. Estimating the global incidence of traumatic brain injury. J Neurosurg. 2018;130(4):1080-1097.

22. Tardif PA, Moore L, Boutin A, Dufresne P, Omar M, Bourgeois G, et al. Hospital length of stay following admission for traumatic brain injury in a Canadian integrated trauma system: A retrospective multicenter cohort study. Injury. 2017 Jan;48(1):94-100.

23. Farrell CA. Management of the paediatric patient with acute head trauma. Paediatr Child Health. 2013 May 1;18(5):253-8.

24. McCrory P, Meeuwisse WH, Aubry M, Cantu RC, Dvorak J, Echemendia RJ, et al. Consensus statement on concussion in sport - the 4th International Conference on Concussion in Sport held in Zurich, November 2012. PM\&R. 2013;5(4):255-279.

25. Maboreke T, Banhwa J, Pitcher RD. An audit of licensed Zimbabwean radiology equipment resources as a measure of healthcare access and equity. Pan Afr Med J. 2019 Oct 1;34:60.

26. Tandon PN, Ramamurthi R. Textbook of Neurosurgery. Vol. 1. JP Medical Ltd; 2012.

27. Andrade FP, Montoro R, Oliveira R, Loures G, Flessak L, Gross R, et al. Pediatric minor head trauma: do cranial CT scans change the therapeutic approach? Clinics. 2016 Oct; 71(10):606-10.

28. Jones K, Patrick G. When is it safe to forego a CT in kids with head trauma? J Fam Pract. 2010 Mar;59(3):159-64. 
29. Le TH, Gean AD. Neuroimaging of traumatic brain injury. Mt Sinai J Med. 2009 Apr;76(2):145-62.

30. Case ME. Inflicted traumatic brain injury in infants and young children. Brain Pathol. 2008;18:571-82.

31. Sun $Q$, Shi $Y$, Zhang F. Pediatric skull fractures and intracranial injuries. Exp Ther Med. 2017;14(3):1871-1874.

32. Liu X, You C, Lu M, Liu J. Growing skull fracture stages and treatment strategy: Clinical article. J Neurosurg Pediatr. 2012 Jun 1;9(6):670-5.
33. Parizel PM, Philips CD. Traumatic Neuroemergency: Imaging Patients with Traumatic Brain Injury - An Introduction. In: Hodler J, Kubik-Huch RA, von Schulthess GK, editors. Diseases of the Brain, Head and Neck, Spine 2020-2023: Diagnostic Imaging. Cham: Springer International Publishing; 2020;77-92.

34. Corley J, Barthèlemy EJ, Lepard J, Alves JL, Ashby J, Khan T, et al. Comprehensive Policy Recommendations for Head and Spine Injury Care in Low-and Middle-Income Countries. World Neurosurg. 2019;132:434. 